\title{
The impact of HIV status and antiretroviral treatment on TB treatment outcomes of new tuberculosis patients attending co- located TB and ART services in South Africa: a retrospective cohort study
}

\author{
Mweete D. Nglazi ${ }^{1,2,3^{*}}$, Linda-Gail Bekker ${ }^{1}$, Robin Wood ${ }^{1}$ and Richard Kaplan ${ }^{1}$
}

\begin{abstract}
Background: The implementation of collaborative TB-HIV services is challenging. We, therefore, assessed TB treatment outcomes in relation to HIV infection and antiretroviral therapy (ART) among TB patients attending a primary care service with co-located ART and TB clinics in Cape Town, South Africa.

Methods: In this retrospective cohort study, all new TB patients aged $\geq 15$ years who registered and initiated TB treatment between 1 October 2009 and 30 June 2011 were identified from an electronic database. The effects of HIV-infection and ART on TB treatment outcomes were analysed using a multinomial logistic regression model, in which treatment success was the reference outcome.

Results: The 797 new TB patients included in the analysis were categorized as follows: HIV- negative, in 325 patients (40.8\%); HIV-positive on ART, in 339 patients (42.5\%) and HIV-positive not on ART, in 133 patients (16.7 \%). Overall, bivariate analyses showed no significant difference in death and default rates between HIV-positive TB patients on ART and HIV-negative patients. Statistically significant higher mortality rates were found among HIVpositive patients not on ART compared to HIV-negative patients (unadjusted odds ratio (OR) 3.25; $95 \%$ confidence interval (CI) 1.53-6.91). When multivariate analyses were conducted, the only significant difference between the patient categories on TB treatment outcomes was that HIV-positive TB patients not on ART had significantly higher mortality rates than HIV-negative patients (adjusted OR 4.12; $95 \% \mathrm{Cl}$ 1.76-9.66). Among HIV-positive TB patients ( $n=472), 28.2 \%$ deemed eligible did not initiate ART in spite of the co-location of TB and ART services. When multivariate analyses were restricted to HIV-positive patients in the cohort, we found that being HIV-positive not on ART was associated with higher mortality (adjusted OR 7.12; $95 \% \mathrm{Cl} 2.95-18.47$ ) and higher default rates (adjusted OR 2.27; 95 \% Cl 1.15-4.47).

Conclusions: There was no significant difference in death and default rates between HIV-positive TB patients on ART and HIV negative TB patients. Despite the co-location of services $28.2 \%$ of 472 HIV-positive TB patients deemed eligible did not initiate ART. These patients had a significantly higher death and default rates.
\end{abstract}

Keywords: Tuberculosis, HIV/AIDS, Treatment outcomes, Integrated TB/HIV care, TB treatment, Antiretroviral therapy

\footnotetext{
*Correspondence: mweete.nglazi@mrc.ac.za

${ }^{1}$ The Desmond Tutu HIV Centre, Institute of Infectious Disease and Molecular

Medicine and the Department of Medicine, Faculty of Health Sciences, University of Cape Town, Cape Town, South Africa

${ }^{2}$ International Union against Tuberculosis and Lung Disease, Paris, France

Full list of author information is available at the end of the article
}

(c) 2015 Nglazi et al. Open Access This article is distributed under the terms of the Creative Commons Attribution 4.0 International License (http://creativecommons.org/licenses/by/4.0/), which permits unrestricted use, distribution, and reproduction in any medium, provided you give appropriate credit to the original author(s) and the source, provide a link to the Creative Commons license, and indicate if changes were made. The Creative Commons Public Domain Dedication waiver (http://creativecommons.org/publicdomain/zero/1.0/) applies to the data made available in this article, unless otherwise stated. 


\section{Background}

Tuberculosis (TB) is a global epidemic, with an estimated 9.0 million new TB cases and 1.5 million deaths in 2013[1]. The global burden of TB falls heaviest on 22 low- and middle-income countries, including those in sub-Saharan Africa, where TB is fuelled by the HIV/ AIDS epidemic [1, 2]. In South Africa, there is a high burden of both TB and HIV [1-3], and a high HIVassociated TB case fatality rate [4].

In high TB and HIV prevalence settings such as South Africa, patients accessing TB services can be broadly categorized as HIV-negative TB patients or HIV-positive TB patients. In terms of optimal case management, both patient groups require standardized anti-tuberculosis treatment, while HIV-positive TB patients also require trimethoprim-sulphamethoxazole (co-trimoxazole) prophylaxis and antiretroviral treatment (ART). ART results in a 64-95\% reduction in mortality risk [5] and should be initiated early after starting anti-tuberculosis treatment [6-8]. Compared to their HIV-negative peers, HIV-positive TB patients are a challenge to TB services, as they are more likely to have diagnostic delays, are more likely to be infectious for longer and, if not properly managed, may also have poorer TB treatment outcomes [9]. Therefore, HIV infection has the potential to profoundly impact on $\mathrm{TB}$ treatment outcomes and is often the main reason for failure to meet control targets in high HIV settings.

In order to control TB in high HIV prevalence settings, the World Health organization (WHO) has recommended TB/HIV collaborative activities, whose objectives are to create mechanisms for collaboration between TB and HIV/AIDS programs, reduce the burden of TB among people living with HIV and reduce the burden of HIV among TB patients [10]. The interpretation of this recommendation varies as demonstrated in a systematic review that described five different models of TB/HIV service integration in low-and middle- income countries, ranging from efficient referral between services, to collaboration between HIV and TB services in the same health facility, and to fully integrated services [11]. The ultimate goals of the models of integration are to reduce rates of mortality, default and relapse; improve rates of $\mathrm{TB}$ cure and to prevent rates of drug resistance. However, in practice challenges remain in the implementation of TB/HIV collaborative activities. For instance, ART uptake may be delayed due to patients having high CD4 counts, drug stockout, patients' fear of drug interactions and overlapping side effects [12], fear of clinicians and national health policy [13]. In addition, the lack of integration of TB and HIV services at all levels in the health system may negatively impact the provision of care [14].
Numerous studies from sub-Saharan Africa have examined the impact of HIV infection on TB treatment outcomes. These studies have yielded mixed results. Some studies have demonstrated poorer TB treatment outcomes in HIV-positive TB patients when compared to HIV-negative TB patients [15-20], while others found that TB treatment outcomes did not differ between the two groups [21, 22]. In addition, the benefit of ART on TB treatment outcomes has been demonstrated in results from the above-cited randomized controlled trials [6-8] and observational studies [19, 23, 24]. Also, a recent systematic review of studies conducted in subSaharan Africa and elsewhere showed the benefit of ART on TB mortality, and indicated a 44 to $71 \%$ reduction in TB mortality risk [25].

TB mortality among HIV-positive TB patients is one of the key indicators that measures the impact of collaborative TB/HIV activities [26]. With the advent of ART, it has become increasingly clear that HIV-positive TB patients are not a homogeneous group, and TB mortality during TB treatment will differ between HIV-positive TB patients on ART and those not on ART. However, to date, there has been no study on TB mortality in HIVpositive TB patients on ART relative to HIV-negative TB patients. Also, to date, there has been no study on TB mortality in HIV-positive TB patients not on ART relative to HIV-negative TB patients.

The aim of the study, therefore, was to establish whether there was a difference in the TB treatment outcomes (mortality and treatment default) in HIV-positive patients on ART compared to HIV-negative TB patients and also among HIV-positive patients not on ART compared to HIV-negative TB patients attending co-located TB services in Cape Town, South Africa. In addition, we aimed to examine impact of ART status and CD4 status on TB treatment outcomes among HIV-positive TB patients.

\section{Methods}

\section{Population and design}

This was a retrospective cohort study conducted at the Nyanga Community Health Centre. The Nyanga Community Health Centre is situated in the Klipfontein health sub-district, Cape Town, South Africa. An estimated 420, 000 people [27] live in this predominantly low-income urban community, which had an antenatal HIV-1 prevalence rate of $24 \%$ in 2009 [28]. This nurserun, doctor supported service provides TB and ART care in two separate clinics run by different health authorities but in the same building and has done so since the introduction of an ART service in 2008. The Cape Town City Health department was responsible for the TB services in this clinic while the Western Cape Provincial Department of Health introduced and managed the ART service. 
While ART and TB services were not fully integrated in this clinic, the adherence support and the monitoring and evaluation systems were partially integrated and all patients starting ART or TB treatment were reviewed at a weekly multidisciplinary team meeting which was attended by TB and HIV staff. TB treatment was dispensed by trained TB nurses under the supervision of a clinician while ART was provided by a team comprised of two clinical nurse practitioners and a doctor. This study was conducted after the introduction of the ART services to the clinic.

\section{Inclusion and exclusion criteria}

We included all new adult TB patients (aged $\geq 15$ years) who registered and initiated TB treatment between 1 October 2009 and 30 June 2011. We excluded those for whom treatment outcomes were inconclusive (14 unknown and 14 transferred out) or who failed treatment $(n=20)$. We also excluded those for whom HIV status was unknown $(n=13)$.

\section{Data collection}

Data from the Cape Town City Health electronic TB register (ETR.net) were compared with that from the Western Cape Department of Health's electronic eKapa TB and ART database and any differences were resolved by reviewing patient folders and paper-based TB registers. The data are not freely available but permission for access was obtained from Cape Town City Health and Western Cape Department of Health. Variables for all patients meeting the inclusion criteria were obtained from the synchronized electronic TB register database. Variables included TB registration number, registration date, age, gender, HIV status, CD4 count at TB diagnosis, ART status and TB treatment outcome. Ethical approval for anonymized data collection was obtained from the Research Ethics Committees of the University of Cape Town and the International Union against Tuberculosis and Lung Disease.

\section{Outcome measures and definitions}

For the purpose of this study, internationally recommended definitions for TB treatment outcomes (classified as either cured, treatment completed, died, defaulted or transferred out) [29] were used, in addition to the category "unknown". Cure was defined as the presence of a negative sputum smear at the last month of treatment and at least on one other occasion during the course of treatment. Treatment completion referred to a patient who completed treatment, but for whom smear examination results were not complete enough to classify the patient as cured; or based on clinical, radiological and complementary examination criteria in those patients who did not produce sputum for a smear examination. Treatment success referred to the combined number of patients belonging to the categories "cured" and "treatment competed". Death was defined as all-cause mortality occurring after TB diagnosis and before the end of treatment. A patient was defined as a defaulter when he or she did not collect medicines for two or more consecutive months.

\section{Anti-tuberculosis and antiretroviral therapy}

Standardized anti-tuberculosis regimens for new adult TB cases consisted of a combination of rifampicin, isoniazid pyrazinamide and ethambutol during the two initial months ("intensive phase") followed by rifampicin plus isoniazid during four months ("continuation phase") [30].

Antiretroviral therapy was offered according to the South African ART guidelines that were updated once during the study period. Before April 2010, staff at both TB and ART services followed the 2004 South African ART guidelines which recommended that patients with CD4 counts of 50-200 cells/ $\mu \mathrm{L}$ should delay ART until after 2 months of starting TB treatment, while those with a CD4 count $<50$ cells $/ \mu \mathrm{L}$ or with serious comorbidities should commence ART as soon as possible after at least 2 weeks of TB treatment [31]. After April 2010, the clinic staff were advised to adopt the 2010 South African ART guidelines, which recommended that TB patients with CD4 cell counts $<100$ cells $/ \mu \mathrm{L}$ or WHO stage IV should commence ART within 2 weeks of eligibility, and those with CD4 cell counts $\leq 350$ cells/ $\mu \mathrm{l}$ should commence ART within 2-8 weeks of starting TB treatment [32].

\section{Statistical analysis}

Patient characteristics were tabulated and stratified by HIV and ART status (categorized as HIV-positive on ART, HIV-positive not on ART and HIV-negative). The chi-square test or Fisher's exact test were used to compare the distribution of categorical variables. The Kruskal-Wallis test or Wilcoxon rank-sum was used to compare the distribution of continuous variables.

The effects of HIV status, ART status and CD4 count on TB treatment outcome were examined using multinomial logistic regression models. In the multinomial logistic regression analysis, "treatment success" was the reference category for the dependent variable, being compared with the other categories (default versus treatment success; death versus treatment success). Independent variables were as follows: age (continuous); gender (male or female); type of TB (smear-negative pulmonary tuberculosis, smear-positive pulmonary tuberculosis or extra-pulmonary tuberculosis); CD4 count $(<50$, 50-199, 200-349 or $\geq 350$ cells/ $\mu \mathrm{L}$ ); HIV status (HIVpositive on ART, HIV-positive not on ART or HIV- 
negative) and ART status (HIV-positive on ART or HIVpositive not on ART).

All analyses were performed using STATA 12.1 (StataCorp, College Station, Texas, USA), and the level of significance was set at $P<0.05 .95 \%$ confidence intervals were also calculated throughout.

\section{Results}

A total of 918 new TB patients $\geq 15$ years were registered between October 2009 and June 2011 (Fig. 1). The new TB patients $(n=61)$ for whom HIV status was unknown; tuberculosis treatment completion status was inconclusive (unknown, transferred out) or who failed tuberculosis treatment were exclude from the analysis (Fig. 1). We also excluded 60 patient categorized as follows: not eligible for ART, in 29 and unknown ART eligibility in 31 patients. This left 797 patients who formed the patient cohort in the study. HIV status in this sample was categorized as follows: HIV- negative, in 325 patients (40.8\%); HIV-positive on ART, in 339 patients (42.5\%) and HIV-positive not on ART, in 133 patients (16.7\%).

The proportion of patients who were female was higher among patients categorized as HIV-positive on ART and HIV positive not on ART $(60.8 \%$ and $60.2 \%$, respectively) (Table 1). The proportion of patients who had smear-positive TB was higher among those HIVnegative $(P<0.001)$. In contrast, no significant differences were found in the distribution of age for each category. The death rate was higher among HIV-positive not on ART compared to the other categories $(P<0.001)$ (Table 1).
Among HIV-positive TB patients $(n=472)$, the median CD4 count was higher in patients categorized HIV-positive not on ART than HIV-positive on ART $(P<0.0001)$ (Table 1$)$. Just over one quarter $(28.2 \%)$ of HIV-positive TB patients deemed eligible did not initiate ART during their TB treatment (Fig. 1).

The findings of multinomial logistic regression analysis of the factors associated with treatment outcomes in new TB patients can be found in Table 2 . The odds ratio (OR) for death in relation to treatment success was found to be significantly higher in patients HIV positive not on ART (adjusted OR 4.12; $95 \%$ confidence interval (CI) 1.76-9.66) than in those HIV-negative. Increased age was associated with higher death rates in relation to treatment success (adjusted OR 1.04; 95 \% CI 1.02-1.07) but reduced default rates in relation to treatment success (adjusted OR 0.98 ; 95 \% CI 0.96-1.00). In addition, being female was associated with lower default rates in relation to treatment success (adjusted OR 0.57; $95 \% \mathrm{CI}$ 0.35-0.91).

Table 3 shows the findings of the multinomial regression analysis of the factors associated with treatment outcomes in HIV-positive TB patients. The odds ratio for death in relation to treatment success was found to be higher in patients HIV-positive not on ART (adjusted OR 7.38; $95 \%$ CI 2.95-18.47) than in those HIV-positive on ART. Similarly, the odds ratio for default in relation to treatment success was found to be higher in patients HIV positive not on ART (adjusted OR 2.27; 95 \% CI 1.15-4.47) than in those HIV positive on ART. In addition, increase age was associated with higher death rates in relation to treatment success (adjusted OR 1.05; 95 \% CI 1.01-1.10).

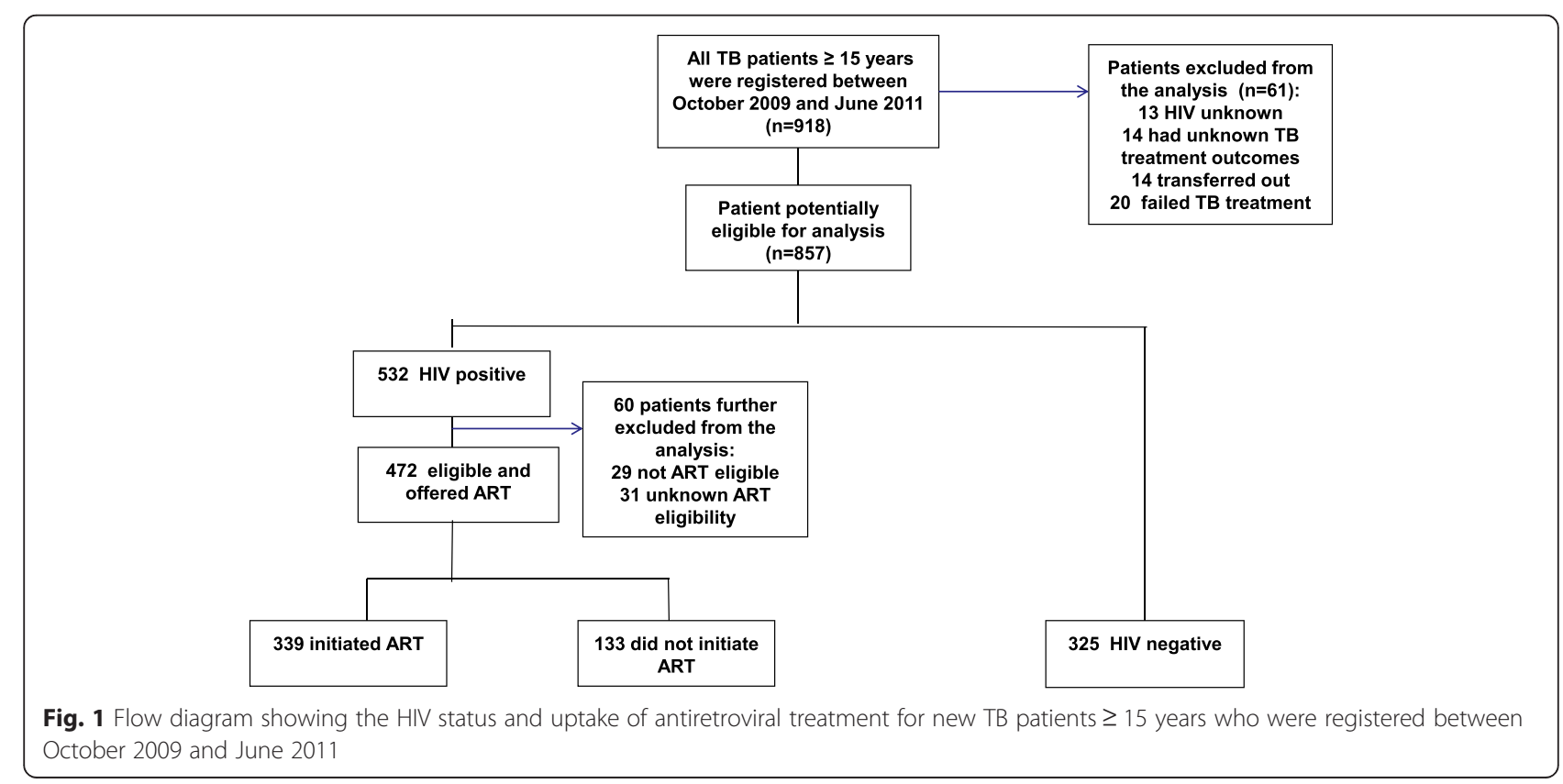


Table 1 Patient characteristics by HIV status among 797 new TB patients $\geq 15$ years who were registered between October 2009 and June 2011

\begin{tabular}{|c|c|c|c|c|c|c|}
\hline & $\begin{array}{l}\text { Total } \\
\text { N (\%) }\end{array}$ & $\begin{array}{l}\text { HIV positive on ART } \\
N(\%)\end{array}$ & $\begin{array}{l}\text { HIV positive not on ART } \\
\mathrm{N}(\%)\end{array}$ & $\begin{array}{l}\text { HIV negative } \\
\mathrm{N}(\%)\end{array}$ & Statistical test & $P$-value \\
\hline \multicolumn{7}{|l|}{ Age } \\
\hline Median, IQR & $33(26-42)$ & $33(28-39)$ & $33(27-37)$ & $32(23-48)$ & Kruskal-Wallis & 0.332 \\
\hline \multicolumn{7}{|l|}{ Gender } \\
\hline Female & $408(51.2)$ & $206(60.8)$ & $80(60.2)$ & $122(37.5)$ & \multirow[t]{2}{*}{ Chi-square } & \multirow[t]{2}{*}{$<0.001$} \\
\hline Male & $389(48.8)$ & $133(39.2)$ & $53(39.9)$ & $203(62.5)$ & & \\
\hline \multicolumn{7}{|l|}{ Type of TB } \\
\hline Smear-negative PTB & $242(30.4)$ & $109(32.2)$ & $52(39.1)$ & $81(24.9)$ & \multirow[t]{3}{*}{ Chi-square } & \multirow[t]{3}{*}{$<0.001$} \\
\hline Smear-positive PTB & $357(44.8)$ & $104(30.7)$ & $48(36.1)$ & $205(63.1)$ & & \\
\hline EPTB & $198(24.8)$ & $126(37.2)$ & $33(24.8)$ & $39(12.0)$ & & \\
\hline \multicolumn{7}{|l|}{ CD4 count, cells/ $\mu \mathrm{L}$} \\
\hline Median, IQR & 144 (74-249) & $123(66-203)$ & $223.5(109-386)$ & - & Wilcoxon rank-sum & $<0.0001$ \\
\hline$<200$ & $302(65.0)$ & $247(73.7)$ & $55(42.3)$ & - & \multirow[t]{4}{*}{ Chi-square } & \multirow[t]{4}{*}{$<0.001$} \\
\hline $200-349$ & $115(24.7)$ & $77(23.0)$ & $38(29.2)$ & - & & \\
\hline $350-499$ & $30(6.5)$ & $7(2.1)$ & $23(17.7)$ & - & & \\
\hline$\geq 500$ & $18(3.9)$ & $4(1.2)$ & $14(10.8)$ & - & & \\
\hline \multicolumn{7}{|c|}{ TB treatment outcome } \\
\hline Success $^{\mathrm{a}}$ & $668(83.8)$ & $299(88.2)$ & $96(72.2)$ & $273(84.0)$ & \multirow[t]{4}{*}{ Chi-square } & \multirow[t]{3}{*}{$<0.001$} \\
\hline Defaulted & $88(11.0)$ & $29(8.6)$ & $21(15.8)$ & $38(11.7)$ & & \\
\hline Died & $41(5.1)$ & $11(3.2)$ & 16 | (12.0) & $14(4.3)$ & & \\
\hline Total & 797 (100.0) & $339(42.5)$ & 133 (16.7) & $325(40.8)$ & & - \\
\hline
\end{tabular}

$I Q R$ interquartile range

Percentages may not add up to 100 due to rounding

${ }^{\mathrm{a}}$ Defined as cured and treatment completed

Table 2 Multinomial logistic regression of factors associated with treatment outcomes in new TB patients

\begin{tabular}{|c|c|c|c|c|}
\hline & Defaulted vs. Success ${ }^{\mathrm{a}}$ & Died vs. Success ${ }^{\mathrm{a}}$ & Defaulted vs. Success ${ }^{a}$ & Died vs. Success ${ }^{a}$ \\
\hline & Unadjusted OR (95 \% Cl) & Unadjusted OR (95\% Cl) & Adjusted OR $(95 \% \mathrm{Cl})^{\mathrm{b}}$ & Adjusted OR $(95 \% \mathrm{Cl})^{\mathrm{b}}$ \\
\hline Age, years & $0.98(0.96-1.00)$ & $1.03^{* *}(1.01-1.05)$ & $0.98^{*}(0.96-1.00)$ & $1.04^{* *}(1.02-1.07)$ \\
\hline \multicolumn{5}{|l|}{ Gender } \\
\hline Male & Ref. & Ref. & Ref. & Ref. \\
\hline Female & $0.60 *(0.38-0.94)$ & $1.16(0.62-2.19)$ & $0.57^{*}(0.35-0.91)$ & $1.06(0.55-2.06)$ \\
\hline \multicolumn{5}{|l|}{ Type of TB } \\
\hline EPTB & Ref. & Ref. & Ref. & Ref. \\
\hline Smear-negative PTB & $0.98(0.54-1.77)$ & $0.81(0.36-1.79)$ & $0.88(0.48-1.62)$ & $0.60(0.26-1.39)$ \\
\hline Smear-positive PTB & $0.85(0.49-1.49)$ & $0.61(0.29-1.32)$ & $0.69(0.38-1.26)$ & $0.59(0.26-1.34)$ \\
\hline \multicolumn{5}{|l|}{ HIV status } \\
\hline HIV-negative & Ref. & Ref. & Ref. & Ref. \\
\hline HIV-positive on ART & $0.70(0.41-1.16)$ & $0.72(0.32-1.61)$ & $0.71(0.41-1.23)$ & $0.80(0.33-1.95)$ \\
\hline HIV-positive not on ART & $1.57(0.88-2.81)$ & $3.25^{* *}(1.53-6.91)$ & $1.62(0.88-2.97)$ & $4.12^{* *}(1.76-9.66)$ \\
\hline
\end{tabular}

Ref. reference, EPTB extra-pulmonary tuberculosis, OR odds ratio, $95 \% \mathrm{Cl}, 95 \%$ confidence intervals

${ }^{*} p<.05,{ }^{* *} p<.01,{ }^{* * *} p<.001$

a Success defined as cured and treatment completed

${ }^{\mathrm{b}}$ Adjusted for age, gender, type of TB and HIV 
Table 3 Multinomial logistic regression of factors associated with treatment outcomes in HIV-positive TB patients

\begin{tabular}{|c|c|c|c|c|}
\hline & Defaulted vs. Success ${ }^{a}$ & Died vs. Success ${ }^{a}$ & Defaulted vs. Success ${ }^{a}$ & Died vs. Success ${ }^{a}$ \\
\hline & Unadjusted OR (95 \% Cl) & Unadjusted OR (95 \% Cl) & Adjusted OR (95\% Cl) & Adjusted OR (95\% Cl) \\
\hline Age, years & $1.00(0.97-1.03)$ & $1.04 *(1.01-1.09)$ & $1.00(0.96-1.03)$ & $1.05^{*}(1.01-1.10)$ \\
\hline \multicolumn{5}{|l|}{ Gender } \\
\hline Male & Ref. & Ref. & Ref. & Ref. \\
\hline Female & $0.74(0.41-1.34)$ & $1.08(0.48-2.41)$ & $0.75(0.40-1.40)$ & $1.65(0.66-4.11)$ \\
\hline \multicolumn{5}{|l|}{ Type of TB } \\
\hline EPTB & Ref. & Ref. & Ref. & Ref. \\
\hline Smear-negative PTB & $1.21(0.59-2.45)$ & $1.13(0.44-2.87)$ & $1.05(0.51-2.18)$ & $0.74(0.26-2.07)$ \\
\hline Smear-positive PTB & $0.97(0.46-2.05)$ & $0.92(0.34-2.47)$ & $0.85(0.40-1.82)$ & $0.68(0.23-2.01)$ \\
\hline \multicolumn{5}{|l|}{ CD4 count, cells/ $\mu \mathrm{L}$} \\
\hline$<50$ & Ref. & Ref. & Ref. & Ref. \\
\hline 50-199 & $0.73(0.32-1.67)$ & $0.43(0.16-1.11)$ & $0.79(0.34-1.85)$ & $0.42(0.15-1.17)$ \\
\hline $200-349$ & $0.88(0.36-2.19)$ & $0.31(0.09-1.06)$ & $0.84(0.33-2.15)$ & $0.20^{*}(0.05-0.75)$ \\
\hline$\geq 350$ & $1.20(0.41-3.48)$ & $0.39(0.08-1.91)$ & $0.84(0.26-2.68)$ & $0.14^{*}(0.03-0.77)$ \\
\hline \multicolumn{5}{|l|}{ ART status } \\
\hline HIV-positive on ART & Ref. & Ref. & Ref. & Ref. \\
\hline HIV-positive not on ART & $2.26^{* *}(1.23-4.14)$ & $4.53^{* * *}(2.03-10.10)$ & $2.27^{*}(1.15-4.47)$ & $7.38^{* * *}(2.95-18.47)$ \\
\hline
\end{tabular}

Ref. reference, EPTB extra-pulmonary tuberculosis, OR odds ratio, $95 \%$ Cl $95 \%$ confidence intervals

${ }^{*} p<.05,{ }^{* *} p<.01,{ }^{* * *} p<.001$

${ }^{\text {a }}$ Success defined as cured and treatment completed

In patients with a CD4 count 200-349 cells/ $\mu \mathrm{L}$, compared to those with $\mathrm{CD} 4$ cell counts $<50$ cells $/ \mu \mathrm{L}$, the odds ratio for death in relation to treatment success was low (adjusted OR 0.20; $95 \%$ CI 0.05 0.75). Similarly, the odds ratio for death in relation to treatment success was found to be lower in patients with CD4 count cell counts $\geq 350$ cells cells $/ \mu \mathrm{L}$ (adjusted OR 0.14; $95 \%$ CI 0.03-0.77) compared to those with $\mathrm{CD} 4$ cell counts $<50$ cells $/ \mu \mathrm{L}$.

\section{Discussion}

In this study, that assessed the impact of HIV, ART status and CD4 cell count on TB treatment outcomes among 797 new TB patients in a co-located ART and TB clinic, death and default rates were significantly higher among HIV-positive patients not on ART than HIVnegative patients. However, there were no differences in death and default rates between HIV-positive TB patients on ART and the HIV negative TB patients. ART uptake during the TB treatment episode was shown to significantly improve mortality and default rates for the HIV-positive TB patients.

Relatively poor uptake of ART has been reported in other studies on various forms of integrated ART and TB services and our finding that $28.2 \%$ of 472 HIVpositive TB patients deemed eligible did not initiate ART during TB treatment in spite of co-location of TB and ART services lies within the range of $27.3 \%$ and $62 \%$ reported in sub-Saharan Africa programs providing fully integrated TB and ART services [12, 13, 19, 33] and is lower than the range of $66-86 \%$ reported in geographically separate services [34-36]. Therefore, the barriers to successful uptake of ART seem common to all studies regardless of the model of care applied. These data clearly indicate that ART uptake should be improved within this setting of co-located TB and ART services or that there is a requirement for a different model of integration of services that would provide for a closer monitoring of ART uptake in patients with HIV-associated TB. Owing to the retrospective design of this study, the barriers to ART uptake were unknown.

Our study finding that ART uptake during TB treatment was significantly associated with improved mortality rates, is similar to a study among patients accessing an integrated TB and ART service in Malawi [19] and is in keeping with evidence that ART during TB treatment improves survival from a randomized controlled trial conducted in South Africa [37]. The study findings call for the strengthening of HIV/TB collaborative activities to ensure efficient treatment integration, which could lead to improved TB treatment outcomes HIV-positive TB patients. However, this community health centre has two health authorities rendering either TB or ART services that are not harmonized owing to organizational differences. Therefore, there is a need to unify these separate health authorities at all levels of the health system 
(which range from clinical care to community support and administrative structures) in order for the community health centre to ensure the successful delivery of integrated TB and ART care for HIV-positive TB patients.

Similar to other studies from sub-Saharan Africa and elsewhere [5-8, 37-45], we found that higher CD4 cell counts $(\geq 200$ cells $/ \mu \mathrm{L})$ were associated with reduced mortality, an indication that patients with CD4 counts $<200$ cells $/ \mu \mathrm{L}$ ) should be fast-tracked for ART. This, however, may only be achieved if ART is prescribed and administered by the TB services.

The strength of this study is that it provides an insight into the HIV, ART status and CD4 cell count on TB treatment outcomes among new TB patients attending a TB service co-located within the same facility as an ART service, although the two services remain separately staffed. The study findings, therefore, are useful to inform policy and programs that aim to improve TB treatment outcomes among new patients with HIV-associated TB in this TB service and other comparable settings.

The limitations of the data used in present study must be acknowledged. We used only routinely collected program data which did not have details of HIV-RNA viral loads of patients and antiretroviral treatment histories of patients already on ART at the time of TB diagnosis (such as antiretroviral resistance, virological treatment failure and clinical immunological failure). The study, therefore, could not explore the effect of these factors on TB treatment outcomes. In addition, non-randomized studies are subject to possible residual confounding bias by unmeasured confounders. Due to small numbers, we could not explore the effect of duration on ART or time delay of ART initiation on treatment outcomes. A further limitation of our study was that the routinely collected program data available did not have details regarding $\mathrm{TB}$ culture results or the distribution of drug resistant versus drug sensitive forms of TB in the study population. Therefore, the study could not determine the influence of these factors on TB treatment outcomes.

\section{Conclusions}

In conclusion, this study showed that death rates were similar for HIV-positive TB patients on ART and HIVnegative TB patients but were considerably higher among HIV-positive patients not on ART. Moreover, despite the co-location of TB and ART services in the same building $28.2 \%$ of 472 HIV-positive TB patients who were eligible to start ART did not initiate ART during the TB treatment episode. These patients had significantly higher death rates and default rates. These findings stress the need for an intervention aimed at improving ART uptake targeting both patients and health care providers.

\section{Abbreviations}

TB: Tuberculosis; HIV: Human immunodeficiency virus; ART: Antiretroviral therapy.

\section{Competing interests}

The authors declare that they have no competing interests.

\section{Authors' contributions}

MDN and LGB designed the study. MDN and RK collected the data and MDN did the analyses with input from RK, LGB and RW. RK, LGB and RW developed the research infrastructure. MDN wrote the paper with input from LGB, RW and RK. All authors read and approved the final manuscript.

\section{Acknowledgements}

The authors would like to thank all the TB staff at the Nyanga Community Health Centre and City Health for access to electronic data. The authors would also like to thank the helpful comments and statistical input provided by Dr. Debbie Bradshaw and Ms. Ria Laubscher from the South African Medical Research Council. MDN was supported as an operational research fellow by The International Union Against Tuberculosis and Lung Disease.

\section{Author details}

'The Desmond Tutu HIV Centre, Institute of Infectious Disease and Molecular Medicine and the Department of Medicine, Faculty of Health Sciences, University of Cape Town, Cape Town, South Africa. ${ }^{2}$ International Union against Tuberculosis and Lung Disease, Paris, France. ${ }^{3}$ Burden of Disease Research Unit, South African Medical Research Council, Tygerberg, Cape Town, South Africa.

Received: 28 June 2015 Accepted: 6 November 2015

Published online: 19 November 2015

\section{References}

1. World Health Organization. Global Tuberculosis Report. Geneva: World Health Organization; 2014. http://www.who.int/tb/publications/global_ report/en/. Accessed 25 Jun 2015.

2. Lawn SD, Zumla Al. Tuberculosis Lancet. 2011;378(9785):57-72.

3. UNAIDS. Report on the global AIDS rpidemic 2013. Joint United Nations Programme on HIV/AIDS; 2013. http://www.unaids.org/en/media/unaids/ contentassets/documents/epidemiology/2013/gr2013/UNAIDS_Global_ Report_2013_en.pdf. Accessed 25 Jun 2015.

4. Bekker L-G, Wood R. TB and HIV co-infection: when to start antiretorviral therapy. SA J Contin Med Educ. 2011;29(10):420-6.

5. Lawn SD, Myer L, Edwards D, Bekker LG, Wood R. Short-term and long-term risk of tuberculosis associated with CD4 cell recovery during antiretroviral therapy in South Africa. Aids. 2009;23(13):1717-25.

6. Abdool Karim SS, Naidoo K, Grobler A, Padayatchi N, Baxter C, Gray AL, et al. Integration of antiretroviral therapy with tuberculosis treatment. N Engl J Med. 2011;365(16):1492-501.

7. Blanc FX, Sok T, Laureillard D, Borand L, Rekacewicz C, Nerrienet E, et al. Earlier versus later start of antiretroviral therapy in HIV-infected adults with tuberculosis. N Engl J Med. 2011;365(16):1471-81.

8. Havlir DV, Kendall MA, Ive P, Kumwenda J, Swindells S, Qasba SS, et al. Timing of antiretroviral therapy for HIV-1 infection and tuberculosis. N Engl J Med. 2011;365(16):1482-91.

9. World Health Organization. TB/HIV: A clinical Manual: Stop TB Department, Department of HIV/ AIDS, Department of Child and Adolescent Health and Development. Second editionthth ed. Geneva: World Health Organization; 2004.

10. World Health Organization. WHO Policy on Collaborative TB/HIV Activities: Guidelines for National Programmes and Other Stakeholders. Geneva: World Health Organization; 2012. http://whqlibdoc.who.int/publications/2012/ 9789241503006_eng.pdf. Accessed 25 Jun 2015.

11. Legido-Quigley $H$, Montgomery CM, Khan P, Atun R, Fakoya A, Getahun H, et al. Integrating tuberculosis and HIV services in low- and middle-income countries: a systematic review. Trop Med Int Health. 2013;18(2):199-211.

12. Kumwenda M, Tom S, Chan AK, Mwinjiwa E, Sodhi S, Joshua M, et al. Reasons for accepting or refusing HIV services among tuberculosis patients at a TB-HIV integration clinic in Malawi. Int J Tuberc Lung Dis. 2011;15(12):1663-9. 
13. Kerschberger B, Hilderbrand K, Boulle AM, Coetzee D, Goemaere E, De Azevedo $V$, et al. The effect of complete integration of HIV and TB services on time to initiation of antiretroviral therapy: a before-after study. PLoS One. 2012;7(10), e46988.

14. Okot-Chono R, Mugisha F, Adatu F, Madraa E, Dlodlo R, Fujiwara P. Health system barriers affecting the implementation of collaborative TB-HIV services in Uganda. Int J Tuberc Lung Dis. 2009;13(8):955-61.

15. Banerjee A, Moyo S, Salaniponi F, Harries A. HIV testing and tuberculosis treatment outcome in a rural district in Malawi. Trans R Soc Trop Med Hyg. 1997:91(6):707-8.

16. Sume GE, Hoshen M, Bita G, Kabore S, Nzima VN. Treatment outcome of TB/HIV positive and negative smear positive pulmonary tuberculosis patients treated using daily self-administered therapy in a Cameroonian district hospital. East Afr Med J. 2009;86(10):469-75.

17. Daniel OJ, Alausa OK. Treatment outcome of TB/HIV positive and TB/HIV negative patients on directly observed treatment, short course (DOTS) in Sagamu, Nigeria. Niger J Med. 2006;15(3):222-6.

18. Shaweno D, Worku A. Tuberculosis treatment survival of HIV positive TB patients on directly observed treatment short-course in Southern Ethiopia: a retrospective cohort study. BMC Res Notes. 2012;5:682.

19. Tweya H, Feldacker C, Phiri S, Ben-Smith A, Fenner L, Jahn A, et al. Comparison of treatment outcomes of new smear-positive pulmonary tuberculosis patients by HIV and antiretroviral status in a TB/HIV clinic, Malawi. PLoS One. 2013;8(2):e56248.

20. Njepoume N, Odume B, Suraj A. The impact of HIV syndroms on the treatment outcome of TB cases: results from a state TB programme in Nigeria. 40th Union World Conference on Lung Health, Cancun, Mexico, 2009. Int J Tuberc Lung Dis. 2009;13(12 Suppl 1):S316. Abstract no: PS-94067-07.

21. van den Broek J, Mfinanga S, Moshiro C, O'Brien R, Mugomela A, Lefi M. Impact of human immunodeficiency virus infection on the outcome of treatment and survival of tuberculosis patients in Mwanza, Tanzania. Int J Tuberc Lung Dis. 1998;2(7):547-52.

22. El-Sony Al, Khamis AH, Enarson DA, Baraka O, Mustafa SA, Bjune G Treatment results of DOTS in 1797 Sudanese tuberculosis patients with or without HIV co-infection. Int J Tuberc Lung Dis. 2002;6(12):1058-66.

23. Henegar C, Behets F, Vanden Driessche K, Tabala M, Bahati E, Bola V, et al. Mortality among tuberculosis patients in the Democratic Republic of Congo. Int J Tuberc Lung Dis. 2012;16(9):1199-204.

24. Kaplan R, Caldwell J, Middelkoop K, Bekker L-G, Wood R. Impact of ART on TB case fatality stratified by CD4 count for HIV-positive TB patients in Cape Town, South Africa (2009-2011). J Acquir Immune Defic Syndr. 2014;66(5):487-94.

25. Odone A, Amadasi S, White RG, Cohen T, Grant AD, Houben RM. The impact of antiretroviral therapy on mortality in HIV positive people during tuberculosis treatment: a systematic review and meta-analysis. PLoS One 2014;9(11):e112017. doi:10.1371/journal.pone.0112017.

26. World Health Organization. A guide to monitoring and evaluation for collaborative TB/HIV actitivies. Geneva: World Health Organization, 2015. http://www.unaids.org/sites/default/files/media_asset/2015_guide monitoring_evaluation_collaborative_TB-HIV_activities_en.pdf. Accessed 14 September 2015

27. Statistics South Africa Mid-year Population Estimates. Department of Health, South Africa. Pretoria: Statistics South Africa. 2010. http://www.statssa.gov. za/publications/P0302/P03022010.pdf. Accessed 25 Jun 2015.

28. National Department of Health. 2009 National Antenatal Sentinel HIV and Syphilis Prevalence Survey, South Africa. Pretoria: National Department of Health; 2010.

29. Fujiwara, PI, Dlodlo, RA, Ferroussier, O, Nakanwagi-Mukwaya A, Cesari G., Boillot, E. Implementing Collaborative TB-HIV Activities: A Programmatic Guide. Paris, France: International Union against Tuberculosis and Lung Disease; 2012. http://www.theunion.org/what-we-do/publications/technical/ english/pub_tb-hivquide_eng_web-1.pdf. Accessed 2 Sept 2013.

30. National Department of Health. The South African National Tuberculosis Control Programme Practical Guidelines 2004. Pretoria: National Department of Health; 2004.

31. National Department of Health. National Antiretroviral Treatment Guidelines. Pinetown, South Africa: Jacana Publishers; 2004.

32. National of Health. Clinical Guidelines for the Management of HIV\&AIDS in Adults and Adolescents. Pretoria: National Department of Health; 2010.
33. Pepper DJ, Marais S, Wilkinson RJ, Bhaijee F, De Azevedo V, Meintjes G. Barriers to initiation of antiretrovirals during Antituberculosis therapy in Africa. PLoS One. 2011;6(5), e19484.

34. Takarinda KC, Harries AD, Srinath S, Mutasa-Apollo T, Sandy C, Mugurungi O. Treatment outcomes of adult patients with recurrent tuberculosis in relation to HIV status in Zimbabwe: a retrospective record review. BMC Public Health. 2012;12:124.

35. Lawn SD, Campbell L, Kaplan R, Little F, Morrow C, Wood R. Delays in starting antiretroviral therapy in patients with HIV-associated tuberculosis accessing non-integrated clinical services in a South African township. BMC Infect Dis. 2011;11:258.

36. Zachariah R, Harries AD, Manzi M, Gomani P, Teck R, Phillips M, et al. Acceptance of anti-retroviral therapy among patients infected with HIV and tuberculosis in rural Malawi is low and associated with cost of transport. PLoS One. 2006;1(1):e121.

37. Abdool Karim SS, Naidoo K, Grobler A, Padayatchi N, Baxter C, Gray A, et al. Timing of initiation of antiretroviral drugs during tuberculosis therapy. $\mathrm{N}$ Engl J of Med. 2010;362(8):697-706.

38. Schmaltz CA, Santoro-Lopes G, Lourenco MC, Morgado MG, Velasque Lde S, Rolla VC. Factors impacting early mortality in tuberculosis/HIV patients: differences between subjects naive to and previously started on HAART. PLoS One. 2012;7(9):e45704.

39. Velasco M, Castilla V, Sanz J, Gaspar G, Condes E, Barros C, et al. Effect of simultaneous use of highly active antiretroviral therapy on survival of HIV patients with tuberculosis. J Acquir Immune Defic Syndr. 2009;50(2):148-52

40. Moore D, Liechty C, Ekwaru P, Were W, Mwima G, Solberg P, et al. Prevalence, incidence and mortality associated with tuberculosis in HIVinfected patients initiating antiretroviral therapy in rural Uganda. Aids. 2007;21(6):713-9.

41. Akksilp S, Karnkawinpong O, Wattanaamornkiat W, Viriyakitja D, Monkongdee $\mathrm{P}$, Sitti W, et al. Antiretroviral therapy during tuberculosis treatment and marked reduction in death rate of HIV-infected patients, Thailand. Emerg Infect Dis. 2007;13(7):1001-7.

42. Franke MF, Robins JM, Mugabo J, Kaigamba F, Cain LE, Fleming JG, et al. Effectiveness of early antiretroviral therapy initiation to improve survival among HIV-infected adults with tuberculosis: a retrospective cohort study. PLoS Med. 2011;8(5):e1001029.

43. Sanguanwongse N, Cain KP, Suriya P, Nateniyom S, Yamada N, Wattanaamornkiat W, et al. Antiretroviral therapy for HIV-infected tuberculosis patients saves lives but needs to be used more frequently in Thailand. J Acquir Immune Defic Syndr. 2008;48(2):181-9.

44. Tabarsi P, Saber-Tehrani AS, Baghaei P, Padyab M, Mansouri D, Amiri M, et al. Early initiation of antiretroviral therapy results in decreased morbidity and mortality among patients with TB and HIV. J Int AIDS Soc. 2009;12:14.

45. Varma JK, Nateniyom S, Akksilp S, Mankatittham W, Sirinak C, Sattayawuthipong W, et al. HIV care and treatment factors associated with improved survival during TB treatment in Thailand: an observational study. BMC Infect Dis. 2009:9:42

\section{Submit your next manuscript to BioMed Central and take full advantage of:}

- Convenient online submission

- Thorough peer review

- No space constraints or color figure charges

- Immediate publication on acceptance

- Inclusion in PubMed, CAS, Scopus and Google Scholar

- Research which is freely available for redistribution 